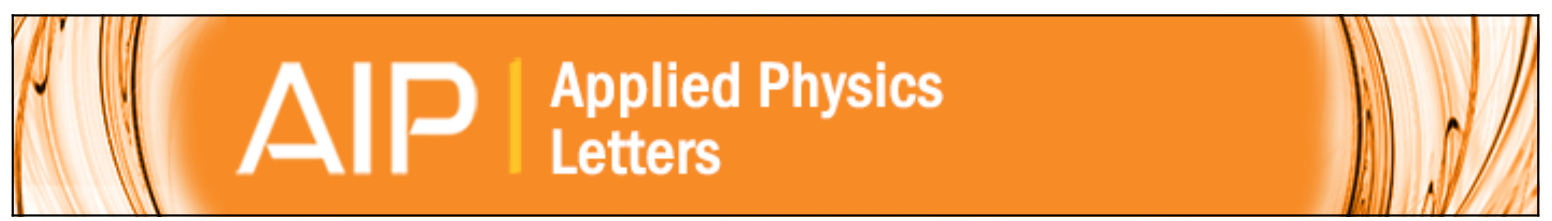

\title{
Electrical current suppression in Pd-doped vanadium pentoxide nanowires caused by reduction in PdO due to hydrogen exposure
}

Byung Hoon Kim, Soon-Young Oh, Hu Young Jeong, Han Young Yu, Yong Ju Yun, Yark Yeon Kim, Won G. Hong, Jeong Yong Lee, and Hae Jin Kim

Citation: Applied Physics Letters 96, 163111 (2010); doi: 10.1063/1.3394003

View online: http://dx.doi.org/10.1063/1.3394003

View Table of Contents: http://scitation.aip.org/content/aip/journal/apl/96/16?ver=pdfcov

Published by the AIP Publishing

\section{Articles you may be interested in}

Opto-electrical properties of Sb-doped p-type $\mathrm{ZnO}$ nanowires

Appl. Phys. Lett. 104, 111909 (2014); 10.1063/1.4869355

Monitoring the Fermi-level position within the bandgap on a single nanowire: A tool for local investigations of doping

J. Appl. Phys. 114, 154308 (2013); 10.1063/1.4826198

Influence of Li-N and Li-F co-doping on defect-induced intrinsic ferromagnetic and photoluminescence properties of arrays of $\mathrm{ZnO}$ nanowires

J. Appl. Phys. 112, 043910 (2012); 10.1063/1.4747929

Formation of monomer to tetramer Ag nanodots in a vanadium oxide nanomesh on $\mathrm{Pd}(111)$

J. Appl. Phys. 112, 034902 (2012); 10.1063/1.4742049

Probing the electrical properties of highly-doped $\mathrm{Al}: \mathrm{ZnO}$ nanowire ensembles

J. Appl. Phys. 107, 074312 (2010); 10.1063/1.3360930

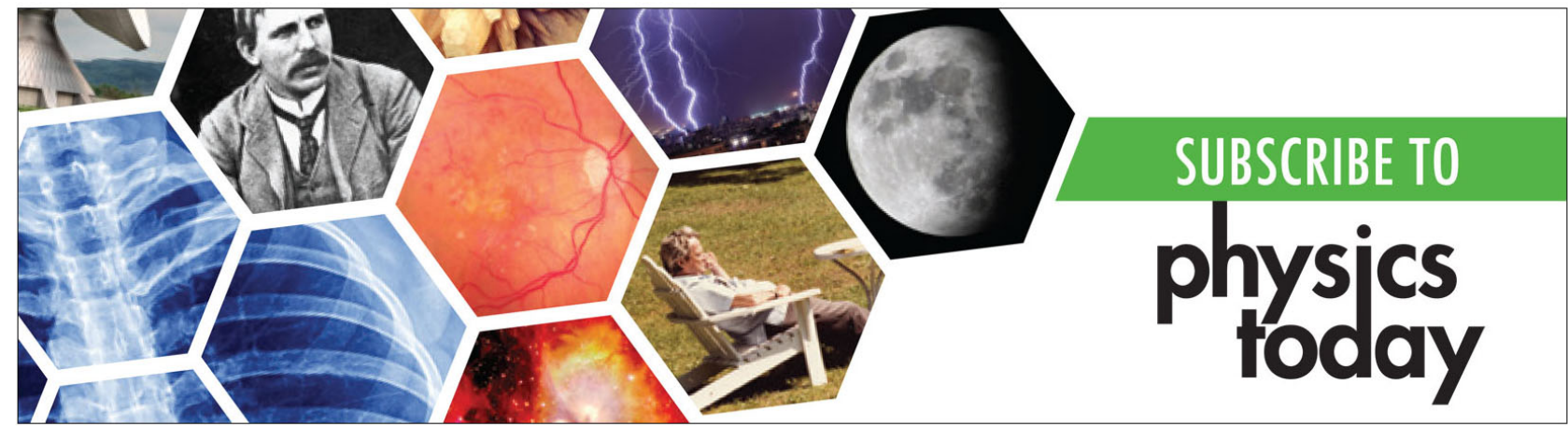




\title{
Electrical current suppression in Pd-doped vanadium pentoxide nanowires caused by reduction in $\mathrm{PdO}$ due to hydrogen exposure
}

\author{
Byung Hoon Kim, ${ }^{1, a)}$ Soon-Young $O{ }^{1},{ }^{1}$ Hu Young Jeong, ${ }^{2}$ Han Young Yu, ${ }^{1, b)}$ Yong Ju Yun, ${ }^{1}$ \\ Yark Yeon Kim, ${ }^{1}$ Won G. Hong, ${ }^{1, a)}$ Jeong Yong Lee, ${ }^{2}$ and Hae Jin Kim ${ }^{3}$ \\ ${ }^{1}$ Electronics and Telecommunications Research Institute (ETRI), Daejeon 305-700, Republic of Korea \\ ${ }^{2}$ Department of Materials Science and Engineering, KAIST, Daejeon 305-701, Republic of Korea \\ ${ }^{3}$ Korea Basic Science Institute, Daejeon 305-333, Republic of Korea
}

(Received 3 December 2009; accepted 23 March 2010; published online 22 April 2010)

\begin{abstract}
$\mathrm{Pd}$ nanoparticle-doped vanadium pentoxide nanowires (Pd-VONs) were synthesized. Electrical current suppression was observed when the Pd-VON was exposed to hydrogen gas, which cannot be explained by the work function changes mentioned in previous report such as Pd-doped carbon nanotubes and $\mathrm{SnO}_{2}$ nanowires. Using the x-ray photoelectron spectroscopy, we found that the reduction in $\mathrm{PdO}$ due to hydrogen exposure plays an important role in the current suppression of the Pd-VON. (C) 2010 American Institute of Physics. [doi:10.1063/1.3394003]
\end{abstract}

Vanadium pentoxide nanowires (VONs) have attracted a great deal of attention since they were first synthesized ${ }^{1}$ due to their possible applications in the field of the nanoelectronic devices. VONs have been considered for use in electrochromic devices, ${ }^{2}$ lithium-ion batteries, ${ }^{3}$ actuators, ${ }^{4}$ and sensors. ${ }^{5,6}$ One specific property of VON, the hydrogen sensing property, deserves focus because hydrogen is the most commonly identified material as a possible alternative energy carrier in the future due to its light weight, abundance, and pollution-free combustion when used as fuel. Pd nanowires are also known as an efficient sensor for hydrogen, ${ }^{7,8}$ detecting hydrogen gas by the dilation of Pd grains during hydrogen adsorption. Moreover, it is well established that Pd catalyst dissociates hydrogen molecules if there are three or more hydrogen vacancies. ${ }^{9}$ Using the hydrogen sensing property of $\mathrm{Pd}$, carbon nanotubes ${ }^{10-12}$ and $\mathrm{SnO}_{2}$ nanowires ${ }^{13}$ have been functionalized with $\mathrm{Pd}$ particles to improve the performance of hydrogen sensing. The decrease of the work function of $\mathrm{PdH}_{\mathrm{x}}$ compared to that in pure $\mathrm{Pd}$ has been suggested by the hydrogen sensing mechanism of Pd-doped singlewalled carbon nanotubes and $\mathrm{SnO}_{2}$ nanowires. Therefore, the current of Pd-functionalized $n$-type (or $p$-type) semiconducting nanowires increases (or decreases) due to exposure to hydrogen gas. Here, we report that the current suppression of Pd-doped VONs (Pd-VONs) occurs under a hydrogen atmosphere, even though VONs are known as an $n$-type semiconductor. Using $\mathrm{x}$-ray photoelectron spectroscopy study, we found that the current suppression in the $I-V$ characteristics of the Pd-VON is ascribed to the reduction in $\mathrm{PdO}$ on the VON. In the reduction process of $\mathrm{PdO}$, electrons are transferred from the VON to PdO, and then water molecules are produced on the surface of the material. This electron transfer causes a decrease in the current in the Pd-VON.

The Pd-VONs were prepared in accordance with the previously presented procedure of synthesizing Ag-doped vanadium pentoxide nanofibers. ${ }^{14}$ The Pd-VONs were synthesized by dissolving $100 \mu \mathrm{L}(420 \mu \mathrm{mol})$ of vanadiumoxytriisopropoxide, $\mathrm{OV}\left(\mathrm{OC}_{3} \mathrm{H}_{7}\right)_{3}$ in $80 \mathrm{~mL}$ of deionized wa-

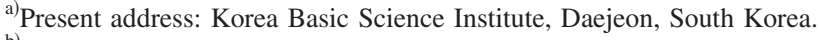

b) Author to whom correspondence should be addressed. Electronic mail: uhan0@etri.re.kr.
}

ter. With this solution, a $15 \mathrm{mg}(90 \mu \mathrm{mol})$ of palladium acetate $\left(\mathrm{CH}_{3} \mathrm{COO}\right)_{2} \mathrm{Pd}$ was mixed in a glass vessel and was stirred for $5 \mathrm{~min}$ at $70{ }^{\circ} \mathrm{C}$. The resulting solution was then kept at ambient conditions. $2 \mu \mathrm{L}$ of Pd-VONs suspension was dropped on the substrate, which is the previously defined Ti/Au electrodes onto $\mathrm{SiO}_{2} / \mathrm{Si}$ highly $p$-doped substrate at a spacing of $1 \mu \mathrm{m}$, a height of $80 / 20 \mathrm{~nm} \mathrm{Ti} / \mathrm{Au}$, and a width of $1 \mu \mathrm{m}$ under the application of ac voltage (frequency $=13 \mathrm{MHz}$, Vpeak to peak $=5 \mathrm{~V}$ ) between electrodes for 5-20 s. $\mathrm{N}_{2}$ gas was blown on the sample for $1 \mathrm{~min}$ to dry the solvent. The electrical transport measurements were carried out using a semiconductor characterization system (4200-SCS, Keithley). For TEP measurements, a low frequency ac steady-state method was used with a 182 nanovoltmeter (Keithley) and 220 current source (Keithley). Transmission electron microscopy (TEM) images were obtained using a $300 \mathrm{kV}$ JEOL JEM 3010 with $0.17 \mathrm{~nm}$ point resolution at $\sim 10^{-8}$ Torr of pressure. X-ray photoelectron spectroscopy (XPS) spectra were recorded using an XPS spectrometer (XPS, VG Scientific. ESCALAB 200R) with an Al-K $\alpha$ source $(\mathrm{h} \nu=1486 \mathrm{eV})$.

From the TEM study, Pd doping on VON was identified. The high-resolution TEM image shows nanoparticles with diameters of 2-3 nm that are attached to the surface of amorphous vanadium oxide nanowires with a width of $\sim 10 \mathrm{~nm}$ [Fig. 1(a)]. The lattice fringes can be seen in the nanoparticles, as shown in the magnified image of Fig. 1(a), indicating the presence of nanocrystals. The spacing of the fringe, an interplanar spacing of $0.23 \mathrm{~nm}$, corresponds to that of the $\{111\}$ planes of Pd (JCPDS data No. 87-0637), which have cubic symmetry with the $F m 3 m$ space group.

We found that the Pd-VONs also show an $n$-type behavior $S_{300 \mathrm{~K}}=-53.8 \pm 0.07 \mu \mathrm{V} / \mathrm{K}$ from thermopower $(S)$ measurement at room temperature because the $S$ is sensitive to the sign of dominant carriers. Figure 1(b) shows the timedependent current variation in the Pd-VON network during hydrogen exposure. The current was significantly suppressed under exposure to hydrogen gas (big arrow) and did not recover, even in a vacuum condition (small arrow). This suppression was also shown in the $I-V$ curve [the inset of Fig. 1(b)] before (blue line) and after (red line) hydrogen exposure. At $3 \mathrm{~V}$, the current decreased from $\sim 800 \mathrm{nA}$ in a 

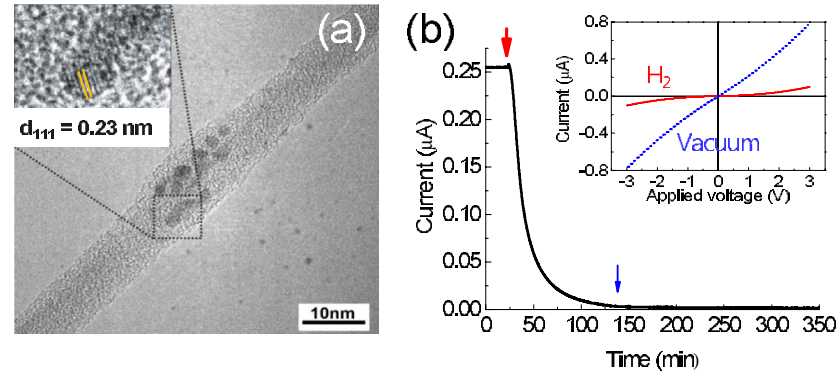

FIG. 1. (Color online) (a) A transmission electron microscopic image of Pd-doped VON shows that the diameter of a single VON modified by nanoparticles is close to $10 \mathrm{~nm}$. The magnified image shows that the crystallized nanoparticles $(2-3 \mathrm{~nm})$ are palladium particles whose interplanar spacing is $0.23 \mathrm{~nm}$ (between the yellow lines). (b) The current variation in the hydrogen adsorption of the Pd-VONs network with a pressure of 1 atm (big arrow). The current does not recover, even under a high vacuum (small arrow). This behavior is also shown in the $I-V$ curve in the inset.

vacuum to $\sim 100 \mathrm{nA}$ in hydrogen atmosphere. This behavior is not consistent with that of other Pd-decorated nanowires. In other words, the lowering of the work function of $\mathrm{PdH}_{\mathrm{x}}$ compared to Pd causes the electrons to be transferred from $\mathrm{Pd}$ to the nanowires. As a result, the current increases (or decreases) in the case of $n$-type (or $p$-type) nanowires. In order to find the current variation in the Pd-VONs during exposure to other gases, we also measured the gas-dependent $I-V$ characteristics in the presence of $\mathrm{He}, \mathrm{Ar}, \mathrm{N}_{2}$, and $\mathrm{O}_{2}$ (Fig. 2). The variation in the current is quite small even at 10 atm; a pressure increase induces a current increase for all gases except oxygen. These behaviors are similar to the pressure-dependent current variation in pure VON. ${ }^{6}$ However, when exposed to hydrogen gas, the $I-V$ characteristics of the Pd-VONs were quite different from those of the VON.

In order to find the mechanisms for the current suppression of the Pd-VONs in a hydrogen atmosphere, we performed an XPS study of the Pd-VONs before and after hydrogen exposure. The amount of the three species $(\mathrm{V}-\mathrm{O}-\mathrm{V}$, $\mathrm{V}-\mathrm{OH}$, and $\mathrm{H}-\mathrm{O}-\mathrm{H})$ is compared by the $\mathrm{O} 1 s$ spectra of the Pd-VONs before and after hydrogen exposure [Figs. 3(a) and

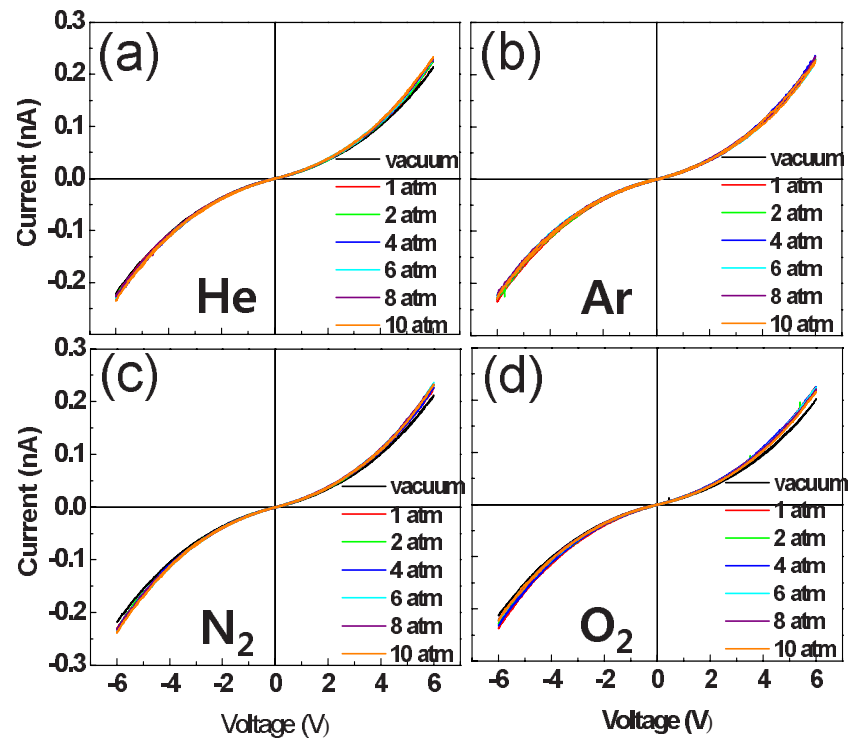

FIG. 2. (Color online) Pressure-dependent $I-V$ curves with various gases, (a) $\mathrm{He}$, (b) $\mathrm{Ar}$, (c) $\mathrm{N}_{2}$, and (d) $\mathrm{O}_{2}$. These results were obtained from a Pd-VON network.

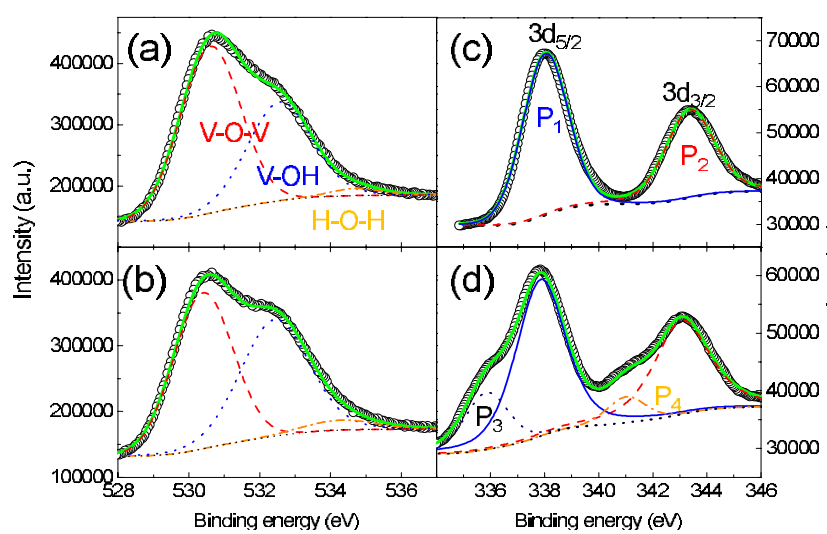

FIG. 3. (Color online) The XPS spectra for O $1 s$ of the Pd-VONs (a) before and (b) after hydrogen exposure. The three species of bonding, V-O-V (red dashed line), $\mathrm{V}-\mathrm{OH}$ (blue dotted line), and $\mathrm{H}-\mathrm{O}-\mathrm{H}$ (orange dashed-dotted line), are shown in the $\mathrm{O} 1 s$ spectra. The amount of $\mathrm{V}-\mathrm{O}-\mathrm{V}$ bonding decreases but that of $\mathrm{V}-\mathrm{OH}$ and $\mathrm{H}-\mathrm{O}-\mathrm{H}$ bondings increase due to the hydrogen exposure of Pd-VONs. (c) and (d) show the XPS spectra for Pd $3 d$ before and after hydrogen exposure, respectively. (c) Before hydrogen exposure, $\mathrm{Pd}$ bonding is not observed but $\mathrm{PdO}$ bonding $\left(\mathrm{P}_{1}\right.$ in blue solid line: $338.02 \mathrm{eV}, \mathrm{P}_{2}$ in red dashed line: $343.35 \mathrm{eV}$ ) is. (d) When exposed to hydrogen, the amount of $\mathrm{PdO}$ bonding decreases and new peaks are developed $\left(\mathrm{P}_{3}\right.$ on the navy blue dotted line: $335.85 \mathrm{eV}, \mathrm{P}_{4}$ on the orange dasheddotted line: $341.02 \mathrm{eV}$ ). The black dotted lines in all of the figures indicate the background.

3(b)]. When the Pd-VONs adsorb hydrogen gas molecules, the $\mathrm{V}-\mathrm{O}-\mathrm{V}$ species decrease but both $\mathrm{V}-\mathrm{OH}$ and $\mathrm{H}-\mathrm{O}-\mathrm{H}$ species increase, indicating that the population of water molecules becomes larger in hydrogen adsorbed Pd-VONs. Figure 3(c) shows the $\mathrm{Pd} 3 d$ spectra. $\mathrm{P}_{1}(338.02 \mathrm{eV})$ and $\mathrm{P}_{2}$ (343.35 eV) peaks correspond to $3 d_{5 / 2}$ and $3 d_{3 / 2}$ for $\mathrm{PdO}$, respectively, ${ }^{15,16}$ which shows $\mathrm{Pd}$ is oxidized as soon as exposed to air. Since the PdO peaks in the XPS study on Pd doped carbon nanotubes and $\mathrm{SnO}_{2}$ nanowires have not been observed, ${ }^{17,18}$ the occurrence of PdO in the Pd-VONs can be a key to understanding the current suppression of the PdVON. As the Pd-VONs were exposed to hydrogen gas, $\mathrm{P}_{1}$ and $\mathrm{P}_{2}$ peaks decrease the binding energy by $0.2 \mathrm{eV}$ [Fig. 3(d)]. This chemical shift means that the $\mathrm{PdO}$ is reduced due to hydrogen adsorption. Note that two new peaks, $\mathrm{P}_{3}(335.85$ $\mathrm{eV})$ and $\mathrm{P}_{4}(341.02 \mathrm{eV})$, are developed that correspond to the Pd $3 d$ feature. ${ }^{15,16}$ Moreover, the relative weights of the $\mathrm{P}_{1}$ and $\mathrm{P}_{2}$ species decrease from $60.8 \%$ and $39.2 \%$ to $46.7 \%$ and $34.3 \%$, respectively, in hydrogen atmosphere. Using the $\mathrm{O} 1 s$ and $\mathrm{Pd} 3 d$ spectra, namely, the increase in water molecules and palladium, the following reaction can be considered:

$$
\mathrm{PdO}+2 \mathrm{H}^{+}+2 \mathrm{e}^{-} \rightarrow \mathrm{Pd}+\mathrm{H}_{2} \mathrm{O} .
$$

$\mathrm{H}_{2}$ molecules are catalytically dissociated on $\mathrm{PdO}$, and electrons are transferred from the VON to PdO. As a result, the reduction in $\mathrm{PdO}$ occurs and water molecules are produced. Hence, the current of the Pd-VON is suppressed by hydrogen adsorption. Since the current does not recover, even in a high vacuum $\left(\sim 10^{-6}\right.$ Torr $)$, we expect that the reverse process of the reaction may not be allowed at room temperature. Besides the reduction in $\mathrm{PdO}$ due to hydrogen, the spillover effect of hydrogen ${ }^{19,20}$ into the VON and strong hydrogen atom trapping inside Pd nanoparticles could be the reason for the current suppression. ${ }^{21}$

In summary, we report the current suppression of PdVONs due to exposure to hydrogen gas, which is not consis- 
tent with the previous reports on Pd doped carbon nanotube, $\mathrm{SnO}_{2}$ nanowires, and even pure VON. Using the XPS spectra of $\mathrm{O} 1 s$ and $\mathrm{Pd} 3 d$ for $\mathrm{Pd}-\mathrm{VON}$, we found that the reduction process of $\mathrm{PdO}$ by $\mathrm{H}_{2}$ adsorption occurs and that the $\mathrm{Pd}$ and $\mathrm{H}_{2} \mathrm{O}$ are produced and that the electrons are required in this reaction. These electrons are transferred from VON to PdO. As a result, the current of $\mathrm{Pd}-\mathrm{VON}$ decreases.

Support for Hae Jin Kim was provided by the Hydrogen Energy R\&D Center, one of the 21st Century Frontier R\&D Program, funded by the Ministry of Science and Technology of Korea (2009K001443).

${ }^{1}$ N. Gharbi, C. Sanchez, J. Livage, J. Lemerle, L. Néjem, and J. Lefebvre, Inorg. Chem. 21, 2758 (1982)

${ }^{2}$ A. Talledo and C. G. Granqvist, J. Appl. Phys. 77, 4655 (1995).

${ }^{3}$ M. Winter, J. O. Besenhard, M. E. Spahr, and P. Novák, Adv. Mater. 10, 725 (1998).

${ }^{4}$ G. Gu, M. Schmid, P.-W. Chiu, A. Minett, J. Fraysse, G.-T. Kim, S. Roth, M. Kozlov, E. Muoz, and R. H. Baughman, Nature Mater. 2, 316 (2003).

${ }^{5}$ H. Y. Yu, B. H. Kang, U. H. Pi, C. W. Park, S.-Y. Choi, and G. T. Kim, Appl. Phys. Lett. 86, 253102 (2005).

${ }^{6}$ B. H. Kim, A. Kim, S.-Y. Oh, S.-S. Bae, Y. J. Yun, and H. Y. Yu, Appl. Phys. Lett. 93, 233101 (2008).
${ }^{7}$ F. Favier, E. C. Walter, M. P. Zach, T. Benter, and R. M. Penner, Science 293, 2227 (2001).

${ }^{8}$ M. Z. Atashbar and S. Singamaneni, Sens. Actuator B 111-112, 13 (2005).

${ }^{9}$ T. Mitsui, M. K. Rose, E. Fomin, D. F. Ogletree, and M. Salmeron, Nature (London) 422, 705 (2003).

${ }^{10}$ J. Kong, M. G. Chapline, and H. Dai, Adv. Mater. 13, 1384 (2001).

${ }^{11}$ S. Mubeen, T. Zhang, B. Yoo, M. A. Deshusses, and N. V. Myung, J. Phys. Chem. C 111, 6321 (2007).

${ }^{12}$ Y. Sun and H. H. Wang, Appl. Phys. Lett. 90, 213107 (2007).

${ }^{13}$ A. Kolmakov, D. O. Klenov, Y. Lilach, S. Stemmer, and M. Moskovits, Nano Lett. 5, 667 (2005).

${ }^{14}$ U. Schlecht, B. Guse, I. Raible, T. Vossmeyer, and M. Burghard, Chem. Commun. 19, 2184 (2004).

${ }^{15}$ Y.-I. Chou, H.-C. Chiang, and C.-C. Wang, Sens. Actuators B 129, 72 (2008).

${ }^{16}$ G. Choi, G. Jin, S.-H. Park, W. Lee, and J. Park, J. Nanosci. Nanotechnol. 7, 3841 (2007).

${ }^{17}$ D. Bera, S. C. Kuiry, M. McCutchen, A. Kruize, H. Heinrich, M. Meyyappan, and S. Seal, Chem. Phys. Lett. 386, 364 (2004).

${ }^{18}$ Y. Shen, T. Yamazaki, Z. Liu, D. Meng, T. Kikuta, N. Nakatani, M. Saito, and M. Mori, Sens. Actuators B 135, 524 (2009).

${ }^{19}$ S. Khoobiar, J. Phys. Chem. 68, 411 (1964).

${ }^{20}$ M. Boudart, J. Mol. Catal. A: Chem. 138, 319 (1999).

${ }^{21}$ K. Kobayashi, M. Yamauchi, H. Kitagawa, Y. Kubota, K. Kato, and M. Takata, J. Am. Chem. Soc. 130, 1828 (2008). 